\title{
Una mirada al crimen de genocidio en las jurisdicciones latinoamericanas*
}

\author{
Elizabeth Santalla Vargas** \\ http://dx.doi.org/10.21503/lex.v9i8.395
}

* La versión original de este artículo se publicó en inglés en la Revista International Criminal Law Review 10(4), (2010), 441-452. Esta traducción y publicación cuenta con la autorización del editor, Prof. Dr. Kai Ambos, traducción al español de la autora.

** Profesora de Derecho Penal Internacional en el Curso Miguel Grau, Lima, mayo de 2011; ha sido Visitante Profesional en la División de Cuestiones Preliminares de la Corte Penal Internacional; al presente, es miembro del equipo jurídico de la Dirección de Reivindicación Marítima de Bolivia.

Las opiniones vertidas en este artículo se efectúan a título personal y no comprometen ninguna posición institucional. 



\section{Introducción}

El genocidio es un crimen que ha sido recogido por la mayor parte de los códigos penales latinoamericanos mucho antes de la adopción del Estatuto de Roma. La criminalización del genocidio en Latinoamérica se ha apartado, en gran parte de los casos, de la definición de la Convención sobre el Genocidio con relación al actus reus, principalmente respecto a los grupos protegidos. No obstante ello, la jurisprudencia existente no brinda mayores luces sobre las razones o justificaciones de dicha desviación; es más bien inconsistente, en algunas instancias. La implementación del Estatuto de Roma ofrece señales mixtas con relación a las tendencias jurídicas y políticas en Latinoamérica en torno al alcance del crimen de genocidio. El hecho de que la codificación de los crímenes de lesa humanidad hubiera adquirido momentum con la entrada en vigor del Estatuto de Roma repercute en la creciente necesidad de reflexionar sobre la coherencia de la criminalización en el derecho interno de los core crimes del derecho penal internacional.

La legislación penal interna en Latinoamérica se caracteriza por un déficit de criminalización de las conductas constitutivas de crímenes contra el Derecho Internacional. ${ }^{1}$ Dicho déficit presenta, sin embargo, una excepción general con el crimen de genocidio. En efecto, la criminalización del genocidio puede retrotraerse a la mayor parte ${ }^{2}$ de los Códigos Penales de la región que fueran adoptados a partir de la década de los 70 - en algunos casos incluso antes $^{3}$ - y, así, resulta independiente de la negociación del Estatuto de Roma de la Corte Penal Internacional (de aquí en adelante: "Estatuto de Roma”) y de su subsiguiente implementación.

\footnotetext{
Cabe reconocer que el debate concerniente a la implementación del Estatuto de la CPI (o Estatuto de Roma) ha dado lugar a la incorporación de los crímenes de jurisdicción de la CPI, con la adopción de legislación de implementación en algunos casos a saber: Argentina, Uruguay, Brasil. Y en la mayor parte de los casos, dicho debate ha impulsado la elaboración de proyectos de legislación; por ejemplo, en Bolivia, Perú y Ecuador.

Venezuela y Ecuador aún no han tipificado el genocidio.

Brasil y México tipificaron el genocidio en 1956 y 1957, respectivamente.
} 
Este artículo, sin ánimo de constituir una revisión exhaustiva, explorará las formas de criminalización del genocidio y sus correspondientes interpretaciones en las jurisdicciones latinoamericanas vis-à-vis la definición actual del genocidio en el Derecho Internacional. Se prestará particular atención a los elementos constitutivos que se apartan de la definición internacional en correlación con las interpretaciones jurisprudenciales (nacionales) disponibles.

\section{Definición y contexto}

La Convención para la Prevención y Sanción del Delito de Genocidio (1948) acuñó la definición de genocidio en el Derecho Internacional. ${ }^{4}$ Esta definición fue posteriormente adoptada por el Estatuto de Roma que reconoció el genocidio como uno de los "crímenes más graves de trascendencia para la comunidad internacional en su conjunto." ${ }^{5} \mathrm{El}$ artículo 6 del Estatuto de Roma define el genocidio, en consonancia con la Convención sobre el Genocidio, ${ }^{6}$ de la siguiente manera:

A los efectos del presente Estatuto, se entenderá por "genocidio" cualquiera de los actos mencionados a continuación, perpetrados con la intención de destruir total o parcialmente a un grupo nacional, étnico, racial o religioso como tal:

(a) matanza de miembros del grupo

(b) lesión grave a la integridad física o mental de los miembros del grupo

(c) sometimiento intencional del grupo a condiciones de existencia que hayan de acarrear su destrucción física, total o parcial

(d) medidas destinadas a impedir nacimientos en el seno del grupo

(e) traslado por la fuerza de niños del grupo a otro grupo

La existencia de la Convención sobre el Genocidio puede atribuirse al hecho de que los Tribunales de Nuremberg restringieron la noción de crímenes de lesa humanidad a su vinculación con el conflicto armado. ${ }^{7}$ En efecto, la Carta de los Tribunales de Nuremberg requería que las conductas punibles tuvieran un nexo con el conflicto armado. Desarrollos

4 Sobre el background histórico, véase, por ejemplo, W. Schabas, “The 'Odious Scourge': Evolving Interpretations of the Crime of Genocide’, en R. Smilth (ed.), The American Genocide, (2006), pp. 93-106.

5 Art. 5(1), Estatuto de Roma.

6 La definición de la Convención sobre el Genocidio fue anteriormente incorporada en los Estatutos de los Tribunales Penales Internacionales ad-hoc: Art. 4(2) del Estatuto del Tribunal Penal Internacional para la antigua Yugoslavia; Art. 2(2) del Tribunal Penal Internacional para Ruanda.

7 Schabas, nota supra 4, p. 105. 
subsiguientes, sin embargo, abandonaron dicho nexo; a saber: la Ley No. 10 del Consejo de Control y el Estatuto del Tribunal Penal Internacional para Ruanda, en tanto que el Estatuto del Tribunal Penal Internacional para la antigua Yugoslavia lo mantuvo. ${ }^{8}$ En esa misma tendencia evolutiva, el Estatuto de Roma ha dejado de lado el nexo con el conflicto armado, reflejando que el Derecho Internacional consuetudinario reconoce que los crímenes de lesa humanidad, así como el genocidio, pueden cometerse en tiempos de paz (como de guerra).

En dicho contexto, la raison d'être del genocidio puede justificarse solamente por el dolo especial -de destruir en todo o en parte- cualquiera de los grupos protegidos: nacional, étnico, racial o religioso, que caracteriza la definición. Si bien el dolo especial es generalmente aceptado como un elemento de mens rea inherente a la definición -aunque con acercamientos divergentes en cuanto a su interpretación, los grupos protegidos se han constituido en el elemento crucial para aquéllos que abogan por expandir el alcance del tipo de genocidio. ${ }^{9} \mathrm{El}$ contexto latinoamericano es un vívido ejemplo de esta discusión.

Varios países en la región, especialmente El Salvador, Nicaragua, Guatemala, Perú y Colombia, vivieron varias décadas de confrontación que, en varios casos, alcanzaron el umbral de un conflicto armado no internacional. Colombia atraviesa al presente por un proceso de justicia de transición que se suscita dentro del aún persistente, si bien reducido, conflicto armado. Dichos conflictos armados involucraron, en términos generales, la existencia de ataques sistemáticos contra la población civil y, en varios casos, contra determinados grupos políticos, como parte de una política de Estado. ${ }^{10}$ Asimismo, la llamada "doctrina de la seguridad nacional", que sirvió de justificativo para el surgimiento de regímenes represivos en la década de los 70, fue motivada y moldeada políticamente. ${ }^{11}$ Dicho contexto podría explicar la expansión del alcance de la definición del genocidio adoptada por varias legislaciones penales en la región, principalmente respecto de la incorporación del grupo político y de otros grupos aún más generales (como parte de los grupos protegidos), aspecto que se analizará más adelante.

8 Para mayor información de contexto e interpretación, véase, por ejemplo, H. von Hebel, 'Crimes Against Humanity under the Rome Statute', en P. van Krieken (ed.), Refugee Law in Context: The Exclusion Clause, (1999), p. 105 - 107.

9 Véase, por ejemplo: D. Feierstein, 'Las violaciones sistemáticas a los derechos humanos en América Latina: la necesidad de pensar estos conceptos desde el "margen latinoamericano", Foro Regional sobre Prevención del Genocidio <http:// www.nodo50.org/codoacodo/feirstein.pdf>. También: B. van Schaack, "The Crime of Political Genocide: Reparing the Genocide Convention's Blind Spot', (1997) 106 (7) Yale L.J. 2259; L.J. Leblanc, 'The United Nations Genocide Convention and Political Groups: Should the United States Propose and Amendment?’, (1988) 13 Yale J. Int'l L. 268.

10 Feierstein, ibid, 3.

11 Ibid, nota supra 9, 7. 


\section{Tipos penales sobre genocidio en las jurisdicciones nacionales}

Si bien el dolus specialis ${ }^{12}$ es inherente a todos los tipos penales sobre genocidio analizados en este artículo, las desviaciones de la definición internacional giran en torno al actus reus -entendido en el sentido de abarcar tanto los grupos protegidos como las modalidades de comisión. ${ }^{13}$

Algunas legislaciones nacionales siguen el lenguaje empleado por la Convención sobre el Genocidio. Este es el caso de Argentina ${ }^{14}$ y Brasil ${ }^{15}$; por el contrario, México ${ }^{16}$ y Cuba, ${ }^{17}$ si bien reconocen los cuatro grupos protegidos de la Convención sobre el Genocidio, establecieron ciertas variaciones en el actus reus. En realidad, la mayor parte de las legislaciones nacionales han alterado la definición, tornándola más o menos inclusiva. ${ }^{18}$ Ejemplos del primer caso son las legislaciones que extienden la categoría de los grupos protegidos, incluyendo los "grupos políticos", los "grupos sociales" y varios otros grupos. En cambio, las definiciones menos inclusivas son el resultado de reducir los grupos protegidos reconocidos por la Convención sobre el Genocidio ${ }^{19}$, principalmente respecto del grupo racial. Y, en varios casos, las legislaciones presentan ambas características (más y menos inclusivas).

El grupo político ha sido incorporado en los Códigos Penales de Colombia, ${ }^{20}$ Panamá $^{21} \mathrm{y}$ Costa Rica ${ }^{22}$. Corresponde subrayar que a tiempo de incluir al grupo político, el tipo penal colombiano restringió su alcance a aquellos grupos políticos que operan dentro del marco de la ley. Esta calificación posteriormente fue declarada inconstitucional por el Tribunal Constitucional, como se comenta más adelante (sección 4.1). Asimismo, es interesante apuntar

12 Para un estudio profundo sobre el elemento de la 'intención de destrucción', véase K. Ambos, 'What Does 'Intent to Destroy' in Genocide Mean?, (2009) 91 (876) International Review of the Red Cross, 833-858.

13 Para un análisis completo sobre los elementos de los crímenes, conforme la codificación del sistema del Estatuto de Roma, véase K. Ambos, 'Selected Issues Regarding the 'Core Crimes' in International Criminal Law', en: International Criminal Law: quo vadis? (Proceedings of the International Conference held in Siracusa, Italy, 28 November - 3 December 2002), (2004), 219-241.

14 La implementación del Estatuto de Roma en Argentina, con relación a los crímenes internacionales, se realizó con remisión directa a los Arts. 6-8 del Estatuto de Roma, que consagran los crímenes. Véase el Art. 2 de la Ley 26200 de Implementación del Estatuto de Roma de 5 de enero de 2007.

15 Ley 2889, de 1 de octubre de 1956.

16 Código Penal Federal, Art. 149 bis (Decreto de 20 de enero de 1967).

17 Código Penal, Art. 116 (modificado por Ley No. 87).

18 W. Ferdinandusse, Direct Application of International Criminal Law in National Courts (2006), 23-4.

19 Ibid.

20 Código Penal, Art. 101 (modificado por Ley No. 599, de 24 de julio de 2000). Para un abordaje sobre su historia legislativa y discusión, véase A. Aponte, 'Informe sobre Colombia', en K. Ambos y E. Malarino (eds.), Persecución Penal Nacional de Crimenes Internacionales en América Latina y España, Montevideo: Fundación Konrad Adenauer (2003), 201 en 207-8.

21 Código Penal, Art. 431 (Ley No. 14, de 18 de mayo de 2007).

22 Código Penal, Art. 375 (Ley No. 4573, de 15 de noviembre de 1970). 
que Bolivia ha entendido el genocidio, como lo manifestara durante las negociaciones de la Convención sobre el Genocidio, en el sentido de incluir la protección de grupos definidos por una ideología en común. ${ }^{23}$ Dicha percepción, sin embargo, no caló en la posterior tipificación interna del genocidio.

El grupo social ha sido incluido en los Códigos Penales del Perú ${ }^{24}$ y Paraguay. ${ }^{25}$ En el último caso, el tipo penal sobre genocidio incluye a una "comunidad", que resulta protegida independientemente a su categorización en cualquiera de los otros grupos. ${ }^{26}$ En esa misma línea, el Código Penal boliviano ha incorporado a las denominadas "masacres sangrientas" ${ }^{27} \mathrm{Y}$ una serie de grupos -fuera de las cuatro categorías convencionales- quedan protegidos por la ley de implementación del Estatuto de Roma en Uruguay; a saber: el grupo político, sindical, y cualquier otro grupo identificado por razones de género, orientación sexual, cultural o social, de edad, discapacidad o salud. ${ }^{28}$

En el otro espectro, algunos Estados han reducido las categorías de grupos protegidos reconocidos por la Convención sobre el Genocidio. El grupo racial fue excluido por los Códigos Penales de Bolivia, ${ }^{29}$ Paraguay, ${ }^{30}$ Perú, ${ }^{31}$ Honduras $^{32}$ y Guatemala. ${ }^{33}$ Nicaragua omitió ambos, tanto los grupos raciales como nacionales, ${ }^{34}$ mientras que el grupo étnico fue omitido en El Salvador ${ }^{35}$ y Costa Rica. ${ }^{36}$

Con relación a las conductas constitutivas de genocidio, las variaciones principalmente se refieren a:

23 Resumen de las actas de la sesión 74th, llevada a cabo en el Palais de Chaillot de París, de 14 de octubre de 1948, UN Doc A/C.6/SR.74 (Medeiros, Bolivia), citado por R. Young, 'How Do We Know Them When We See Them? The Subjective Evolution in the Identification of Victim Groups for the Purpose of Genocide', (2010) 10 International Criminal Law Review 1, en 8 .

24 Código Penal, Art. 319 (modificado por Ley No. 26926, de 19 de febrero de 1998). El grupo racial fue reemplazado por el grupo social sin ninguna explicación o justificación, en el Código Penal adoptado en 1991. Esta fue la primera vez que se tipificó el genocidio en la legislación penal peruana. Véase, C. Caro, 'Informe sobre Perú', en Ambos y Malarino (eds.), nota supra 20, 447 en 448 .

25 Código Penal, Art. 319 (modificado por Ley No. 1160 de 1997).

26 Código Penal, Art. 319.

27 Código Penal, Art. 138 (inicialmente modificado por Ley 1768, de 10 de marzo de 1997). Para un análisis sobre los paralelos entre el Art. 138 y el Art. 6 del Estatuto de Roma, véase E. Santalla Vargas, 'Informe sobre Bolivia', en Ambos y Malarino (eds.), nota supra 20, 83 en 86-7.

28 Ley 18026, de 25 de septiembre de 2006, Art. 16. Para una crítica a la luz del principio de legalidad, véase D. Camaño Viera, 'La Implementación del Estatuto de Roma en el Uruguay', (2008) 1 Boletín Jurídico.

29 Código Penal, Art. 138.

30 Código Penal, Art. 319 (modificado por Ley No. 1160, de 1997).

31 Código Penal, Art. 319.

32 Código Penal, Art. 319 (Decreto 144-83).

33 Código Penal, Art. 376 (Decreto 17/73).

34 Código Penal, Art. 549.

35 Código Penal, Art. 361 (modificado por Decreto Ley 745, de 5 de noviembre de 2008).

36 Código Penal, Art. 375. 
(i) La extensión del traslado por la fuerza de niños del grupo a otro grupo, incluyendo a adultos (Bolivia ${ }^{37}$ y Guatemala ${ }^{38}$ ), y la extensión a cualquier persona (El Salvador), ${ }^{39}$ a cualquier grupo (Uruguay) ${ }^{40}$ y a la comunidad (Paraguay) $;^{41}$

(ii) La sustitución del lenguaje del artículo 6(c), por: "infligir deliberadamente al grupo condiciones de vida inhumanas" (Bolivia), ${ }^{42}$ "condiciones que harían difícil su supervivencia" (El Salvador), ${ }^{43}$ "mantener a los miembros del grupo en condiciones de vida precarias, capaces de causar la extinción, total o parcial, del grupo" (Costa Rica), ${ }^{44}$ y la extensión de esta modalidad de comisión a la privación de recursos indispensables para la supervivencia, a una grave alteración de la salud, al desplazamiento sistemático del lugar de origen, o a condiciones que podrían modificar la forma tradicional de vida (Uruguay); $;^{45}$

(iii) La restricción del lenguaje del artículo 6(d) a: "la imposición de esterilización masiva con el propósito de prevenir la reproducción del grupo" (México); ${ }^{46}$

(iv) La incorporación, como parte del actus reus, de: "embarazo forzoso" (Colombia), ${ }^{47}$ la privación al ejercicio de las costumbres o cultos del grupo (Paraguay), ${ }^{48} \mathrm{y}$ la inclusión de la tortura, desaparición forzada, privación de libertad, violencia sexual, embarazo forzoso, tratos inhumanos o degradantes (Uruguay). ${ }^{49}$

\section{Los elementos constitutivos del tipo de genocidio en la jurisprudencia latinoamericana}

Aunque las sentencias latinoamericanas sobre genocidio -o relacionadas- son escasas, existen algunas que cabe mencionar. ${ }^{50}$ En dicho cometido, se centrará el análisis en los aspectos relevantes de dichas sentencias, distintos de las interpretaciones que, de manera general, se

37 Código Penal, Art. 138.

38 Código Penal, Art. 376.

39 Código Penal, Art. 361.

${ }^{40}$ Ley 18026, de 25 de septiembre de 2006, Art. 16.

41 Código Penal, Art. 319.

42 Código Penal, Art. 138. Para una crítica, véase Santalla Vargas, nota supra 27, p. 87.

43 Código Penal, Art. 361.

44 Código Penal, Art. 375.

45 Ley 18026, de 25 de septiembre de 2006, Art. 16(c). Dichos criterios son una reminiscencia de la Sentencia en Akayesu del Tribunal Penal Internacional para Ruanda, que ejemplificó la expresión "condiciones de existencia que hayan de acarrear su destrucción física" con los escenarios descritos en el Art. 16(c) de la Ley 18026. Véase, Prosecutor v. Jean-Paul Akayesu, Sentencia, Caso No. ICTR-96-4-T, T.Ch. I, 2 de septiembre de 1998, párr. 506.

46 Código Penal Federal, Art. 149 bis.

47 Código Penal, Art. 101.

48 Código Penal, Art. 319.

49 Ley 18026, de 25 de septiembre de 2006, Art. 16(b).

50 Para una revisión completa, con los extractos en español de las Sentencias, véase Fundación para el Debido Proceso Legal, Digesto de Jurisprudencia Latinoamericana sobre Crímenes de Derecho Internacional (2009), 13-28. 
han esbozado respecto de la definición convencional que las sentencias en cuestión también siguen. ${ }^{51}$ No obstante, resulta importante mencionar una de las interpretaciones efectuadas en ese sentido.

A tiempo de referirse al requerimiento del mens rea, y en consonancia con la jurisprudencia internacional, la Corte Suprema de México ha efectuado la distinción entre intención y motivo en el contexto del pedido de extradición por parte de España de Cavallo. La sentencia ha enfatizado que lo relevante para el crimen de genocidio es la prueba de la intención específica de destruir -en todo o parte- uno de los grupos protegidos, al margen de si el propósito detrás de la destrucción es de carácter político, económico, de venganza, etc. ${ }^{52}$ Dicha distinción resulta relevante en vista de la creciente tendencia, particularmente en América Latina, de calificar como genocidio cualquier conflicto que involucre cierto grado de violencia y de víctimas de minorías étnicas o que socialmente sean percibidas como grupos excluidos.

Una de las pocas sentencias que analiza las características del grupo es la referente al llamado caso argentino Circuito Camps y Otros. ${ }^{53}$ El caso se remonta a la dictadura argentina, que comenzó en 1976 e involucró graves violaciones a los Derechos Humanos. Uno de los cuestionamientos que planteó la sentencia era si los miles de víctimas del llamado terrorismo de Estado -que eran principalmente políticos opositores- podía constituir un grupo nacional para efectos del crimen de genocidio. La pregunta se resolvió, de manera afirmativa, sobre la base de la consideración de que el grupo afectado estaba constituido por cualquiera que se opusiera a las visiones políticas de la dictadura, y que la intención detrás de las conductas represivas no eran cambiar la mentalidad dentro del grupo sino, más bien, exterminarlo. ${ }^{54}$

Con el razonamiento anterior, la sentencia parece asimilar al grupo político con el grupo nacional. Dicha posición podría dar lugar a calificar como genocidio los numerosos crímenes cometidos durante los regímenes dictatoriales de la década de los 70, que marcaron la historia de América Latina. Sin embargo, puede considerarse que tal interpretación encierra una nube conceptual que, en última instancia, podría "frustrar, por vía de interpretación, la elección consciente [de la Convención sobre el Genocidio] de una lista exhaustiva de grupos protegidos". 55

51 Véase, por ejemplo, Corte Constitucional de Colombia, Demanda de inconstitucionalidad contra el artículo 322 de la Ley 589 de 2000 (Código Penal), Considerando 3, Sentencia C-177/01, Expediente D-3120, de 14 de febrero de 2001. La Sentencia es enfática sobre la naturaleza de jus cogens atribuida al genocidio. Véase también México, Amparo en revisión promovido por Ricardo Miguel Cavallo, considerando décimo primero.

52 Amparo en revisión promovido por Ricardo Miguel Cavallo, Amparo en Revisión 140/2002, Corte Suprema de Justicia de la Nación de México, 10 de junio de 2003 (considerando décimo primero).

53 Caso 'Circuito Camps' y otros (Miguel Osvaldo Etchecolatz), Causa No. 2251/06, Tribunal Oral en lo Criminal Federal (La Plata), 19 de septiembre de 2006.

54 Ibid., considerando IV.b.

55 C. Kreß, 'The Crime of Genocide under International Law', (2006) 6 International Criminal Law Review 461, p. 476 (traducción libre). 
A pesar del hecho de que, como se viera anteriormente, la desviación más notoria de la definición internacional se refiere a los grupos protegidos en América Latina, la jurisprudencia no ha dado mayores luces respecto del rationale o la justificación de dicha desviación y/o de su alcance de interpretación. En ese escenario, las demandas de inconstitucionalidad de algunos de los elementos constitutivos del tipo de genocidio en Colombia y Bolivia, así como una condena por genocidio en el último caso, merecen mencionarse.

\subsection{El caso colombiano}

La constitucionalidad del tipo de genocidio en Colombia ha sido objeto de revisión judicial en dos ocasiones. El 2001, la Corte Constitucional declaró la inconstitucionalidad de la incorporación de los grupos políticos que operan sólo al margen de la ley, considerando que dicha restricción podía generar impunidad. Dicho de otro modo, la delimitación hubiera constituido una barrera jurídica para persecuciones penales por genocidio en los casos de grupos políticos que pudieran considerarse como grupos irregulares o ilegales. ${ }^{56}$

En otro contexto, la Corte Constitucional confirmó la constitucionalidad de la calificación "graves" del actus reus, i.e. causar lesiones graves a la integridad física o mental de los miembros del grupo, al reafirmar el rationale subyacente en la Convención sobre el Genocidio. Es decir que, teniendo en cuenta el dolo específico y los grupos específicos protegidos por el crimen de genocidio, resulta coherente requerir un cierto grado de gravedad en las lesiones físicas y mentales. ${ }^{57}$

La inclusión del grupo político dentro de los grupos protegidos no ha sido objeto de revisión judicial específica. Sin embargo, a tiempo de pronunciarse sobre las mencionadas demandas de inconstitucionalidad, la Corte Constitucional ha remarcado que el tipo de genocidio no está circunscrito al Derecho Internacional, sino que más bien encuentra su justificación en las mismas protecciones que prevé la Constitución, a saber, en el derecho de asociación y de constitución de grupos u organizaciones políticas, así como en la prohibición de discriminación, inter alia, por opiniones políticas. ${ }^{58}$

\subsection{El caso boliviano}

La expresión “masacres sangrientas” insertada en el artículo 138 del Código Penal boliviano, que tipifica el genocidio, sirvió de sustento legal para la persecución penal de los crímenes

56 Demanda de inconstitucionalidad contra el artículo 322 de la Ley 589 de 2000 (Código Penal), Sentencia C-177/01, Expediente D-3120, Corte Constitucional, 14 de febrero de 2001.

57 Actor: Gonzalo Rodrigo Paz Mahecha, Demanda de inconstitucionalidad contra las expresiones 'grave' contenida en el numeral 1 del artículo 101 y 'graves' contenida en los artículos 137 y 178 de la Ley 599 de 2000, por la cual se expide el Código Penal, Sentencia C-148/05, Corte Constitucional de Colombia, de 22 de febrero de 2005.

58 Ibid. 
cometidos por el ex dictador, Luis García Meza ${ }^{59}$ y sus más cercanos colaboradores, ${ }^{60}$ en el juicio de responsabilidades seguido en su contra. Esto es así, toda vez que las víctimas no correspondían a ninguno de los tres grupos protegidos por el tipo (nacional, étnico y religioso).

Sobre la base de la información disponible, este juicio de responsabilidades constituye la única persecución penal y condena por genocidio lograda hasta ahora en América Latina. Sin embargo, el uso del término "masacres sangrientas", ha sido objeto de crítica por su carencia de certeza jurídica, a la luz del principio de legalidad. ${ }^{61}$ Como apunta Semelin, '[e]xisten varios problemas de definición inherentes a la noción de masacre', ${ }^{62}$ lo que conlleva una serie de dificultades cuando la noción es trasladada a la definición del crimen. Bolivia es un claro ejemplo al respecto.

El juicio de responsabilidades seguido contra Gacía Meza y otros, comprendió varias categorías de crímenes, el más grave de los cuales fue el genocidio. El crimen fue imputado respecto del incidente suscitado en la calle Harrington de La Paz. El 15 de enero de 1981, tuvo lugar un operativo de ejecución extrajudicial en la calle Harrington, donde se llevaba a cabo una reunión secreta del partido de oposición, Movimiento de Izquierda Revolucionario (MIR). Un grupo de agentes armados enviados por el gobierno irrumpió en una casa privada donde se realizaba la reunión y dio muerte a ocho de los nueve líderes políticos que se encontraban desarmados después de que habían sido capturados. El incidente es conocido como "La Masacre de la Calle Harrington".

Las pruebas presentadas llevaron a la conclusión que el incidente había sido parte de un plan para exterminar a los líderes políticos del MIR, diseñado con el conocimiento y participación de García Meza. El operativo de la calle Harrington había sido planeado un día antes, en una reunión llevada a cabo el 14 de enero de 1981. No obstante el hecho de que ni García Meza ni Arce Gomez (entonces Ministro de Gobierno) estuvieran presentes en la reunión, la prueba fue contundente respecto de sus órdenes y conocimiento del plan.

Los mencionados hechos fueron caracterizados, por la sentencia emitida por la Corte Suprema de Justicia el 21 de abril de 1993, como hechos tendentes a la eliminación de

59 Su dictadura abarcó los años 1980-81. La misma es considerada uno de los más nefastos golpes de Estado y de los regímenes de represión en la historia de Bolivia.

60 García Meza Tejada, Luis y Otros (Caso Dirigentes del Movimiento de Izquierda Revolucionario), Corte Suprema de Justicia, Sentencia de 21 de abril de 1993.

61 E. Santalla Vargas, 'Informe sobre Bolivia', en K. Ambos, G. Elsner y E. Malarino (eds.), Justicia de Transición. Con Informes de América Latina, Alemania, Italia y España, Montevideo: Fundación Konrad-Adenauer (2009), 153, pp. 1634.

62 J. Semelin, 'Massacres', en S. Totten y P.R. Bartrop (eds.), The Genocide Studies Reader, Routledge (2009), p. 86. 
un grupo de políticos e intelectuales. Sin embargo, dicha caracterización no fue objeto de explicación en la sentencia respecto del elemento de grupos protegidos del artículo 138 del Código Penal que tipifica el genocidio excluyendo a los grupos raciales y sin protección particular del grupo político. La sentencia tampoco abordó el dolo especial del genocidio. En consecuencia, no existió análisis respecto a si la prueba presentada podía dar lugar a que la Corte Suprema de Justicia concluyera que el acusado(s) tenía la intención de destruir a un grupo protegido, en todo o parte.

Como se mencionara anteriormente, la noción de "masacres sangrientas" insertada en el segundo párrafo del tipo de genocidio (artículo 138 del Código Penal) dio lugar a la imputación y condena del ex dictador y de su Ministro de Gobierno por genocidio, en razón de los hechos perpetrados en la calle Harrington.

El artículo 138 del Código Penal boliviano reza:

El que, con propósito de destruir en todo o parcialmente un grupo nacional, étnico o religioso, diere muerte o causare lesiones a los miembros del grupo, o los sometiere a condiciones de inhumana subsistencia, o les impusiere medidas destinadas a impedir su reproducción, o realizare con violencia el desplazamiento de niños o adultos hacia otros grupos, será sancionado con presidio de diez a veinte años. En la misma sanción incurrirán el o los autores, u otros culpables directos o indirectos de masacres sangrientas en el país. Si el o los culpables fueren autoridades o funcionarios públicos, la pena será agravada con multa de cien a quinientos días. ${ }^{63}$

Sin embargo, la sentencia no arroja luces sobre los elementos objetivos y subjetivos de las "masacres sangrientas", en particular sobre su relación con los elementos del genocidio. ${ }^{64}$ Este cuestionamiento fue objeto de revisión judicial a raíz de un recurso de inconstitucionalidad de la expresión "masacres sangrientas", presentada por un parlamentario el 2006. A pesar de la confusión e incertidumbre que plantea dicha expresión, el Tribunal Constitucional declaró su constitucionalidad. ${ }^{65}$

Los principales argumentos del Tribunal Constitucional pueden resumirse de la siguiente manera: (i) el principio de legalidad no resulta violentado por el segundo párrafo del artículo 138, que constituye lex certa al definir la conducta y su consecuencia. Con relación a

63 Código Penal de Bolivia, Art. 138. (Texto ordenado según Ley No. 1768, de Modificaciones al Código Penal).

64 En la misma línea, véase J. Quigley, The Genocide Convention: an International Law Analysis (2006), 40-1.

65 Leigued Hurtado Diputado Nacional v. Sandra Giordano Presidente de la Cámara de Senadores, Sentencia constitucional 0034/2006, Tribunal Constitucional de Bolivia, 10 de mayo de 2006. 
la definición, el Tribunal Constitucional recurre a la definición de "masacre" del diccionario de la Real Academia Española; ${ }^{66}$ (ii) el segundo párrafo del artículo 138 es distinto del primero toda vez que, como interpreta el Tribunal Constitucional, la noción de "masacres sangrientas" no comparte la intención específica del genocidio (dolus specialis), ni los grupos protegidos contemplados en el primer párrafo del tipo. ${ }^{67}$

La crítica a la sentencia es contundente. ${ }^{68} \mathrm{Si}$ la noción de "masacres sangrientas" no comparte los elementos objetivos ni subjetivos del genocidio, no existe fundamento racional para su inclusión en el tipo de genocidio, de ahí que cualquier persecución penal (y condena) que sobre su base se caracterice como genocidio queda, por decir lo menos, desprovista de legitimidad. Asimismo, si los elementos objetivos y subjetivos de la expresión han de encontrarse en un diccionario, el componente de lex certa del principio de legalidad queda ciertamente erosionado. Por otro lado, llama la atención que el Tribunal Constitucional, en concordancia con el Presidente del Parlamento, estableciera que la implementación de los crímenes del Estatuto de Roma puede ir más allá del Estatuto y ser más protectora a nivel nacional, ${ }^{69}$ cuando la disposición en discusión no era la de implementación sino el artículo 138 del Código Penal - en vigor a tiempo de la redacción de este artículo (julio de 2011) - y que no ha sido modificado desde su incorporación en $1973 .{ }^{70}$

Por otro lado, la asimilación de las masacres con el genocidio queda, en última instancia, en tela de juicio por consideraciones que emergen más allá de un enfoque solamente legal. En efecto, un punto de vista sociológico, sostiene que "[d]ebido a que los grupos son construcciones sociales, no pueden ser ni constituidos ni destruidos simplemente a través de los cuerpos de sus miembros individuales", ${ }^{71}$ de ahí que la destrucción involucre "un nexo entre la destrucción de formas colectivas de vida, de instituciones y daño físico o de otro

66 Sentenciad constitucional, ibid., (sección II.3.2, párrafos segundo y octavo).

67 Ibid, párr. sexto.

68 Para una crítica detallada de la Sentencia, subrayando sus implicaciones respecto de la implementación del Estatuto de Roma, véase E. Santalla Vargas, 'Informe sobre Bolivia', en K. Ambos, E. Malarino y G. Elsner (eds.), Jurisprudencia Latinoamericana sobre Derecho Penal Internacional, Montevideo: Fundación Konrad-Adenauer (2008), 67 pp. 75-81.

69 Sentencia constitucional, nota supra 65, sección II.3.2.

70 La versión original del Código Penal boliviano fue adoptada por Decreto Ley 10426, de 1973. La modificación del crimen - eliminando el controversial párrafo segundo, e incorporando el grupo racial, así como introduciendo otras modificaciones en el actus reus, de conformidad con el Art. 6 del Estatuto de Roma - fue propuesta por la consultoría de implementación del Estatuto de Roma, véase E. Santalla Vargas, 'Implementación del Estatuto de Roma de la Corte Penal Internacional en Bolivia: Análisis del Ordenamiento Jurídico Interno y de los Procesos de Implementación en la Legislación Comparada', en Defensor del Pueblo de Bolivia (ed.), Implementación del Estatuto de la Corte Penal Internacional en Bolivia (2005), 85 p. 119. Véase también, E. Santalla Vargas, 'Informe sobre Bolivia', en K. Ambos, E. Malarino y J. Woischnick (eds.), Dificultades Jurídicas y Políticas para la Ratificación o Implementación del Estatuto de Roma de la Corte Penal Internacional. Contribuciones de América Latina y Alemania, Montevideo: Fundación KonradAdenauer (2006), 99 pp. 121-2.

71 M. Shaw, 'Elements of Genocidal Conflict: Social Groups, Social Destruction and War', en A. Jones (ed.), Genocide in Theory and Law, Sage Publ. (2008), Vol. I, 123 p. 131. 
tipo a los individuos" ${ }^{72}$ Considerando que el término masacre se entiende comúnmente como "una forma de acción, por lo general colectiva, destinada a la eliminación de civiles o no combatientes, incluyendo a hombres, mujeres, niños o adultos mayores incapaces de defenderse", ${ }^{73}$ surge una evidente dicotomía conceptual entre "masacre" y "genocidio".

En todo caso, puede considerarse que la conclusión sociológica está en consonancia con los desarrollos en la jurisprudencia internacional. Como señala Schabas, ${ }^{74}$ la delimitación en Krstić de la definición de genocidio en el derecho internacional consuetudinario "a aquellos actos tendentes a conseguir la destrucción física o biológica de todo o parte del grupo", ${ }^{75}$ resulta opacada por jurisprudencia subsiguiente que ha admitido la comisión de genocidio aun en la ausencia de pruebas de una exterminación física planeada. ${ }^{76}$

\section{Conclusiones}

Si bien este artículo no se ha centrado en la implementación, y con la conciencia de los riesgos involucrados en el intento de escudriñar en intenciones legislativas ante la ausencia de travaux préparatoires específicos, puede efectuarse una afirmación a priori respecto al rationale subyacente a las variaciones que la definición del genocidio ha experimentado, en gran parte de la legislación penal interna en América Latina. El hecho de que los crímenes de lesa humanidad fueran ajenos a las legislaciones internas - argumentablemente hasta la entrada en vigor del Estatuto de Roma, que dio lugar a su implementación o consideración seria - puede explicar porqué los tipos de genocidio no resultaron concordantes con el alcance de la definición de la Convención sobre el Genocidio. ${ }^{77}$

Cabe también tomar en cuenta la fuerte condena moral que conlleva una condena por genocidio, toda vez que dicha condena está estrechamente unida al estigma que el crimen de genocidio ha provocado históricamente.

Como se ilustró anteriormente, los tipos nacionales sobre genocidio en América Latina confirman la estructura del crimen como uno de intención específica que difiere de los grupos protegidos y actos que hacen a la conducta genocida. No obstante, la interpretación jurisprudencial con relación al rationale o justificación de tales enfoques legislativos divergentes es casi inexistente o precaria.

72 Ibid.

73 Semelin, nota supra 62. p. 86.

${ }^{74}$ Ibid, nota supra 4, p. 103.

75 Prosecutor v. Krstić, Sentencia, Caso No. IT-98-33-T, 2 de agosto de 2001, párr. 580.

76 Prosecutor v. Blagojević et al, Sentencia, Caso No. IT-02-60-T, T.Ch.I, 17 de enero de 2005, párr. 650.

${ }_{77}$ La Ley de implementación del Estatuto de Roma de Uruguay constituye una excepción a esta afirmación, como se explicara anteriormente, que ha sobre expandido el alcance del genocidio. Ley 18026, de 15 de septiembre de 2006, Art. 16. 
Queda por ver las opciones jurídicas y políticas que se adoptarán en América Latina en el proceso gradual de adopción de legislación de implementación del Estatuto de Roma. No resulta claro si los Estados optarán por mantener el extendido alcance del genocidio, o evitarán incurrir en yuxtaposiciones peligrosas que podrían surgir principalmente con relación a los crímenes de lesa humanidad, estableciendo parámetros claros entre los crímenes. La tendencia actual ofrece señales mixtas al respecto. ${ }^{78} \mathrm{El}$ tiempo es propicio para reflexionar sobre las razones detrás de la intención de caracterizar una determinada situación como genocidio, en un momento en el que la codificación de los otros core crimes ha alcanzado momentum.

78 Por ejemplo, en tanto que Argentina ha implementado el Estatuto de Roma adoptando la definición de la Convención sobre el Genocidio, Uruguay lo ha hecho expandiendo la noción de genocidio a una amplia gama de grupos, incluyendo los políticos. 


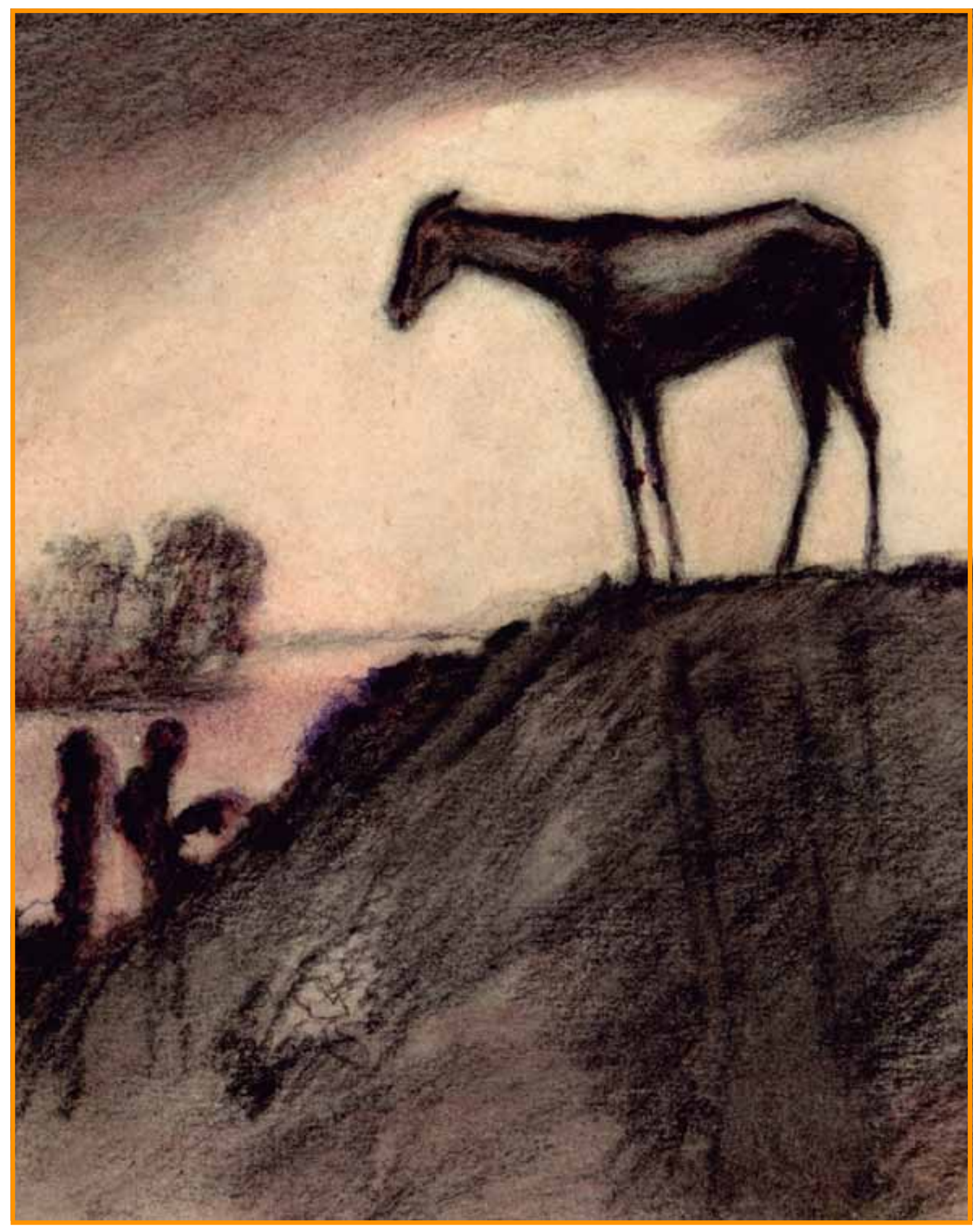

